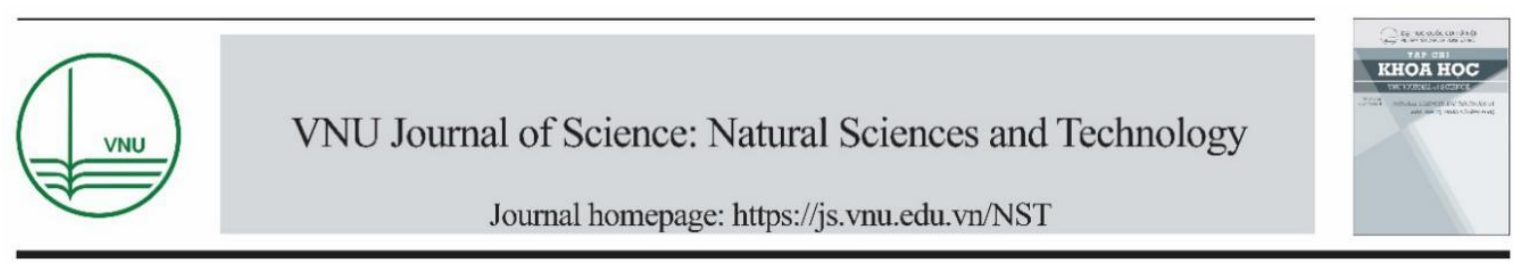

Original Article

\title{
Stereoelectronic Properties of 1,2,4-Triazole-Derived N-heterocyclic Carbenes - A Theoretical Study
}

\author{
Nguyen Van $\mathrm{Ha}^{*}$, Doan Thanh Dat, Trieu Thi Nguyet \\ Faculty of Chemistry, VNU University of Science, 19 Le Thanh Tong, Hanoi, Vietnam
}

Received 05 August 2019; Accepted 06 October 2019

\begin{abstract}
A theoretical study on stereo and electronic properties of a series of six 1,2,4-triazolederived carbenes bearing different N4-substituents, namely isopropyl (1), benzyl (2), phenyl (3), mesityl (4), 2,6-diisopropylphenyl (5) and 1-naphthyl (6), has been carried out. Structures of the six carbenes were first optimized using Gaussian ${ }^{\circledR} 16$ at B3LYP level. Their molecular geometries and electronic structures of the frontier orbitals were examined. The results suggest the similarity in nature of their HOMOs, which all posses $\sigma$ symmetry with respect to the heterocycle and essentially be the lone electron pair on the $\mathrm{C}_{\text {carbene. }}$ Steric properties of the NHCs was also quantified using percent volume burried $\left(\% V_{\text {bur }}\right)$ approach. The NHC 1 with isopropyl N4-substituent was the least bulky one with $\% V_{\text {bur }}$ of 27.7 and the most sterically demanding carbene is $\mathbf{6}$, which has large 2,6diisopropylphenyl substituent $\left(\% V_{\text {bur }}=38.4\right)$. Interestingly, the NHCs with phenyl and 1-naphthyl N4-substituents display flexible steric hindrance due to possible rotation of the phenyl or 1-naphthyl around the N-C single bond. Beside stereoelectronic properties of the NHC, topographic steric map of their complexes with metal were also investigated.
\end{abstract}

Keywords: N-heterocyclic carbene, triazolin-5-ylidene, stereoelectronic properties, percent volume burried.

\section{Introduction}

In the past few decades, N-hetero cyclic carbine (NHC) has remarkably transformed from a merely curiosity-driven laboratory discovery into an essential class of ligand in organometallic chemistry[1-6]. NHC popularity and widespread applications can be attributed to their excellent turnability of steric and electronic properties by changing their $\mathrm{N}$-substituents or the carbene backbone itself [7-8].

Among the four classical type of $\mathrm{N}$ heterocyclic carbenes (Figure 1), imidazole and 1,2,4-triazole derived carbenes are isoelobal since the latter is formed by a mere substitution of a $\mathrm{CH}$ group in the earlier by a nitrogen atom. Despite their similarity in electronic and steric

\footnotetext{
* Corresponding author.

Email address: hanv@ hus.edu.vn

https://doi.org/10.25073/2588-1140/vnunst.4935
} 
properties, it is surprising to notice that the chemistry of 1,2,4-triazole derived carbene is much less explored[9-14] compared to their imidazole-derived cousin.<smiles>[R]N1C=CN([R])C1</smiles>

a)<smiles>[R]N1C=NN([R])C=N1</smiles>

c)

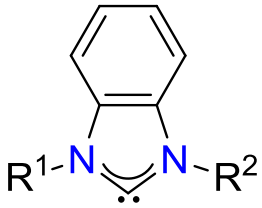

b)<smiles>[R]c1cn([R])cn1</smiles>

d)
Figure 1. Generic structures of the 4 type of classical $\mathrm{N}$-heterocyclic carbenes derived from imidazole (a), benzimidazole (b), 1,2,4-triazole (c) and imidazoline (d).

As a part of our ongoing effort to explore the chemistry and potential application of 1,2,4triazole derived carbene $[15,16]$, we present in this work the theoretical study of steric and electronic properties of a series of six 1,2,4triazole derived carbene bearing different $\mathrm{N}$ substituents (Figure 2).<smiles></smiles>

$$
\begin{aligned}
& \mathrm{R}=\text { isopropyl (1) mesityl (4) } \\
& \text { benzyl (2) 2,6-diisopropylphenyl (5) } \\
& \text { phenyl (3) 1-naphthyl (6) }
\end{aligned}
$$

Figure 2. Structures of the NHCs in this work.

This theoretical study is expected to provide understanding on the stereoelectronic of the triazole-derived carbene under investigation, and hence provide guidance to the choice of $\mathrm{N}$ substituents for the follow-up experimental work on the design of triazole-derived carbene complexes for catalysis application and drug development.

\section{Methodology}

The All the carbenes under studied were first optimized using Gaussian ${ }^{\circledR} 16$ at B3LYP level [17-20]. The 6-31G(d) basis set were employed for all atoms [21,22]. The nature of the stationary optimized points was confirmed to represent minima on energy potential surface by frequency analysis. Kohn-Sham orbitals were obtained directly from these calculations.

The steric hindrance of carbenes and their topographic steric maps were analysed using the web tool SambVca 2 developed by Luigi Cavallo [23]. The optimized structures were taken as input for the calculations. Occupation of the coordination sphere by the carbene, percent volume burried $\% V_{\text {bur, }}$, was calculated using a ghost metal atom coordinated by the carbene with metal-carbon distance of $2.01 \AA$. Topographic steric maps of the carbene on their metal complexes were generated using the same SambVca 2 tool.

\section{Results and discussion}

\subsection{Geometry of the carbenes}

Singlet-state gas-phased optimized geometries of 1-6 are shown in Figure 1. Selected bond lengths and bond angles are listed in Table 1.

All the singlet states of all the 6 carbenes are in perfecty planar geometries. The N1-C5 and $\mathrm{N} 4-\mathrm{C} 5\left(\mathrm{~N}-\mathrm{C}_{\text {carbene }}\right.$ bonds) are in the 1.348$1.353 \AA$ and $1.378-1.386 \AA$ ranges. The $\angle \mathrm{N} 1 \mathrm{C} 5 \mathrm{~N} 4$ angles at the carbene ranging from 100.0-100.2 . $^{\circ}$

Noted that, since the chemistry of 1,2,4triazole derived carbene remains almost unexplored, hence there exist very few experimental parameters for this type of compounds. One example is the first know stable triazole-derived carbene, 1,3,4-triphenyl-1,2,4triazol-5-ylide [24]. In its molecular structure, the $\mathrm{N}-\mathrm{C}_{\text {carbene }}$ distances are $1.351(3) \AA$ and 1.373(4) $\AA$ for N1-C5 and N4-C5, respectively. The $\mathrm{NC}_{\text {carbene }} \mathrm{N}$ angle $(\angle \mathrm{N} 1 \mathrm{C} 5 \mathrm{~N} 4)$ of $100.6(2)^{\circ}$ 
was observed. In general, the theoretically calculated parameters are closely resemble the reported experimental values for 1,3,4-triphenyl1,2,4-triazol-5-ylide.

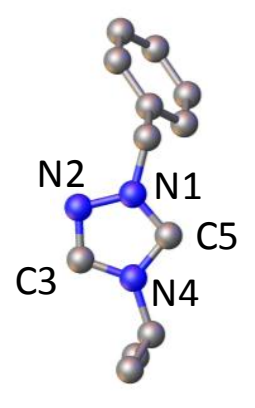

1

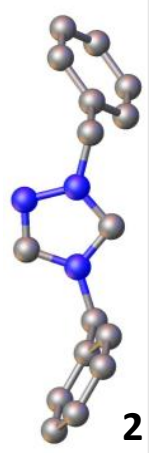

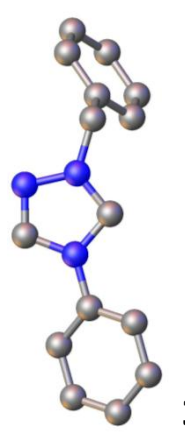

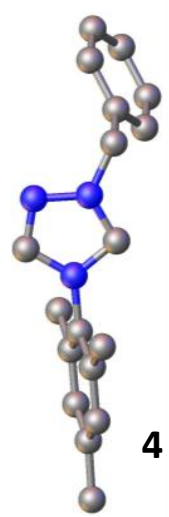

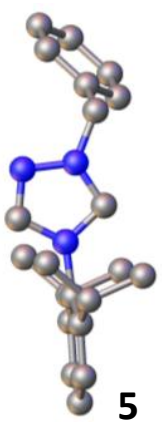

Figure 3. Optimized geometries of 1-6.

Table 1. Sellected bond lengths $(\AA)$ and angles $\left(^{\circ}\right)$

\begin{tabular}{lllllll}
\hline \multirow{2}{*}{ Parameter } & \multicolumn{7}{c}{ NHC } \\
\cline { 2 - 7 } & $\mathbf{1}$ & $\mathbf{2}$ & $\mathbf{3}$ & $\mathbf{4}$ & $\mathbf{5}$ & $\mathbf{6}$ \\
\hline N1-C5 & 1.353 & 1.353 & 1.348 & 1.352 & 1.350 & 1.350 \\
N4-C5 & 1.378 & 1.379 & 1.386 & 1.384 & 1.383 & 1.386 \\
N1-N2 & 1.385 & 1.387 & 1.388 & 1.389 & 1.388 & 1.388 \\
N2-C3 & 1.302 & 1.301 & 1.299 & 1.300 & 1.299 & 1.299 \\
C3-N4 & 1.378 & 1.377 & 1.383 & 1.382 & 1.380 & 1.384 \\
$\angle \mathrm{N} 1 \mathrm{CN} 4$ & 100.2 & 100.1 & 100.2 & 100.0 & 100.2 & 100.0 \\
\hline
\end{tabular}

It is interesting to notice the differences in the orientation of the aromatic $\mathrm{N}$-substituent plane with respect to the plane of the triazole heterocycle ring. The mesityl (in 4) and 2,6diisopropylphenyl (in 5), due to the steric bulk of the methyl and isopropyl substituents, are nearly perpendicular to the triazole ring, forming dihedral angles of $77^{\circ}$ and $90^{\circ}$, in 4 and $\mathbf{5}$ respectively. On the other hand, the phenyl in $\mathbf{3}$ and 1-naphthyl group (in 6) are more flexible and can rotate along the $\mathrm{N}-\mathrm{C}_{\text {aromatic }}$ bond. This is evidenced by dihedral angles of $26^{\circ}$ and $51^{\circ}$ observed in $\mathbf{3}$ and $\mathbf{6}$, respectively. The influence of flexible orientation of the aromatic substituents with respect to the triazole on stereoelectronic properties of the respective carbene will be worth examining more details (vide infra).
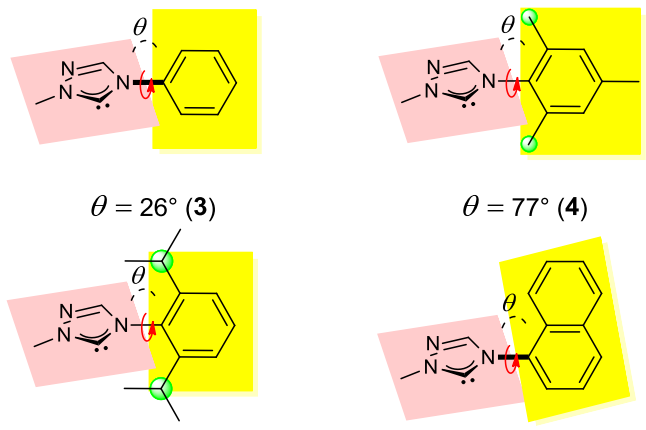

$\theta=90^{\circ}(\mathbf{5})$

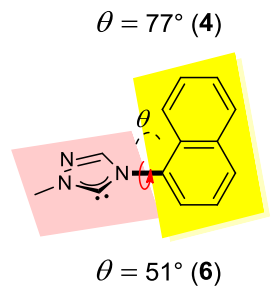

Figure 4. Flexible orientation of phenyl and 1-naphthyl ring with respect to the heterocycle.

\subsection{Electronic properties of the carbenes}

Surfaces of the highest energy occupied molecular orbital (HOMO) and lowest energy 
unorcupied molecular orbital (LUMO) of the carbenes are shown in Figure 5 and their energy levels are plotted in Figure 6.

It can be noted that the LUMOs have the shape and spacial extension varries from one carbene to another. Overall, the LUMOs are largely localized on the aromatic ring of the substituents. There is little to none contribution from the triazole ring to the carbenes LUMOs. In fact, the lowest $\pi$ - unoccupied orbital of the triazole fragment, which in nature are essentially $\mathrm{p}$ orbital of the $\mathrm{C}_{\text {carbene, }}$ lie relatively higher in energy. Such orbitals are indeed LUMO+3 for $\mathbf{1}$, LUMO+5 for $\mathbf{2 , 3}, \mathbf{4}, 5$ and LUMO+6 for $\mathbf{6}$.

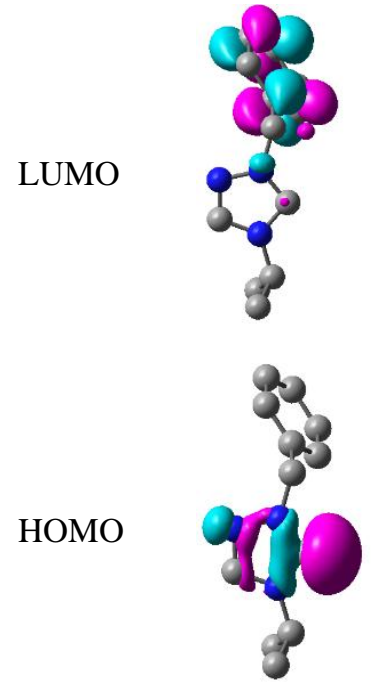

1
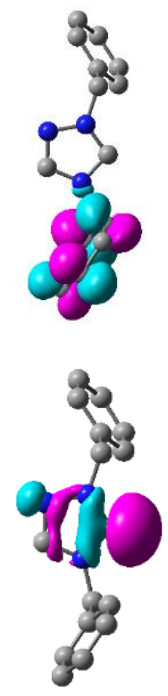

2
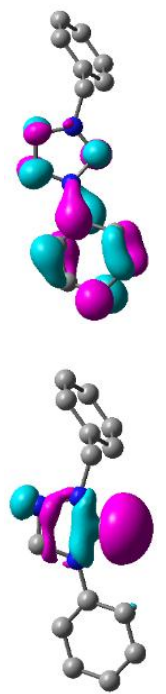

3
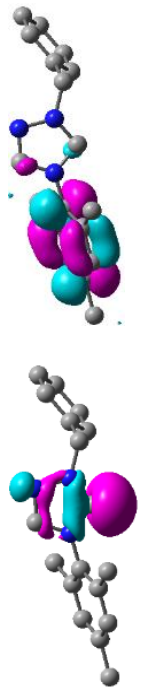

4
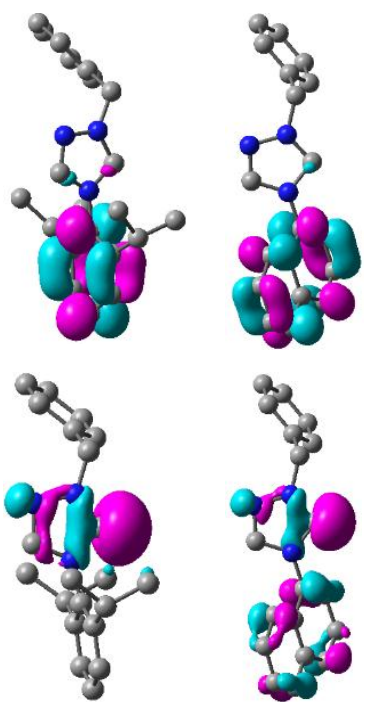

5

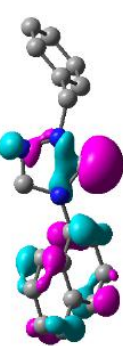

6

Figure 5. Shape of frontier (HOMO and LUMO) molecular orbitals for 1-6.

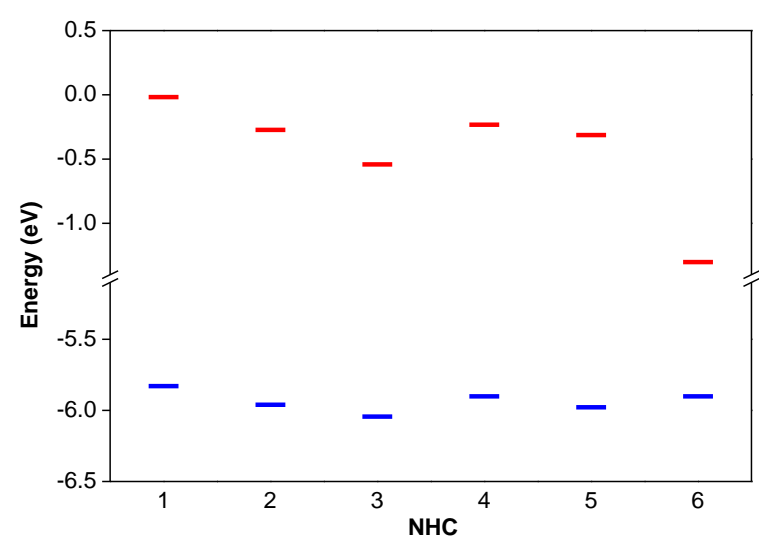

Figure 6. Energy level of HOMO (blue) and LUMO (red) orbitals of the carbenes.

In contrast the the LUMO, the HOMO ortbials are mainly localized on the triazole ring for $1,2,3,4$ and 5 . In case of 6 , small contribution from the naphthyl ring was spotted
(Figure 5). All the HOMO orbitals has $\sigma$ symmetry with respect to the NHC plane and corresponds to the lone pair of the carbene carbon atom. The high energy nature of the lone pair of $\mathrm{C}_{\text {carbene }}$ atom suggests that these orbitals would involve in formation of bonding between carbenes and transition metal ions.

Close examination of the frontier orbitals reveals a significant difference in LUMO energy level, which is in line with the vast difference in their nature and spatial extension. On the other hand, the energy of HOMO energy levels only slightly varries from a NHC to another, and lie in the range from -5.83 to $-6.04 \mathrm{eV}$. The HOMO of $\mathbf{1}$ is highest in energy $\left(\mathrm{E}_{\text {номо }}=-5.83 \mathrm{eV}\right)$ due to the destabilization by positive inductive effect $(+I)$ from the electron donating isopropyl group. Their HOMO energy similarity suggests a relatively similar donor strength for these carbenes. 


\subsection{Steric properties of the carbenes}

Steric hindrance generally play a dominant role in defining metal complex reactivities, especially in catalysis. There exist several methodologies to evaluate ligand steric hindrance, such as Tolman cone angle [25,26], solid angle measure [27], angular symmetric deformation coordinate [28], ligand repulsive energy parameter [29] and percent volume burried $[23,30]$. Among these, percent volume burried are a modern approach, which is convenient to use well accepted in the organometallic research community. Percent volume burried ( $\% V_{\text {bur }}$ ) of a ligand is defined as the percentage of the metal center coordination sphere occupied by that particular ligand (Figure 7).

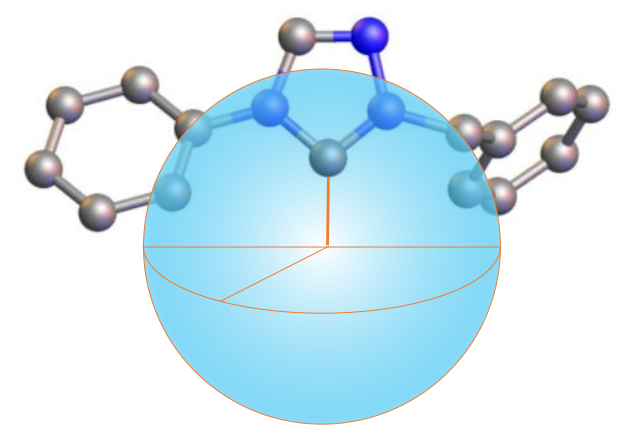

Figure 7. Ligand occupation of the coordination sphere, principle of $\% V_{\text {bur }}$ calculation.

Input for calculation of $\% V_{\text {bur }}$ of a ligand is solid-state $\mathrm{X}$-ray determined molecular structure of its metal complexes or the optimized geometries of the ligand with a ghost metal ion placed at a certain distance from the $\mathrm{C}_{\text {carbene. }}$ Calculation can be performed using SambVca 2, a web-based tool by Luigi Cavallo.

$\% V_{\text {bur }}$ values for the six NHCs are listed in Table 2. It can be noted that $\% V_{\text {bur }}$ is heavily depend on the nature of the $\mathrm{N}$-substituents. The less bulky isopropyl group form a relatively compact carbene 1 with $\% V_{\text {bur }}$ of 27.7. Slighly higher $\% V_{\text {bur }}$ values are found for NHC with benzyl (2, 29.7), 1-naphthyl (6, 29.7), mesityl (4, $31.1)$ and phenyl $(\mathbf{3}, 31.3) \mathrm{N}$-substituents. In line with chemistry intuition, bulky 2,6- diisopropylphenyl group gives rise to the carbene 6, which posseses the highest steric hindrance with $\% V_{\text {bur }}$ of 38.4 .

Table 2. Percent volume burried ( $\left.\% V_{\text {bur }}\right)$ of the NHCs)

\begin{tabular}{cccc}
\hline NHC & $\% V_{\text {bur }}$ & NHC & $\% V_{\text {bur }}$ \\
\hline $\mathbf{1}$ & 27.7 & $\mathbf{4}$ & 31.1 \\
$\mathbf{2}$ & 29.7 & $\mathbf{5}$ & 38.4 \\
$\mathbf{3}$ & 31.3 & $\mathbf{6}$ & 29.7 \\
\hline
\end{tabular}

It has been pointed out that the phenyl (in $\mathbf{3}$ ) and naphthyl (in 6) substituents can rotate around the N-C single bond, and hence posses a certain degree of flexibility in term of their relative orientation to the triazole ring. Such rotational flexibility is expected to translate into a flexible steric bulk for $\mathbf{3}$ and $\mathbf{6}$. In order to probe that sterical flexibily in more details, $\%$ Vbur of $\mathbf{3}$ and $\mathbf{6}$ were calculated using hypothetical structures formed by rotating the respective substituent along the $\mathrm{N}-\mathrm{C}$ bond. The $\% V_{\text {bur }}$ of the ligand is then plotted against the dihedral angle between the triazole ring and plane of the aromatic substituent (Figure 8).

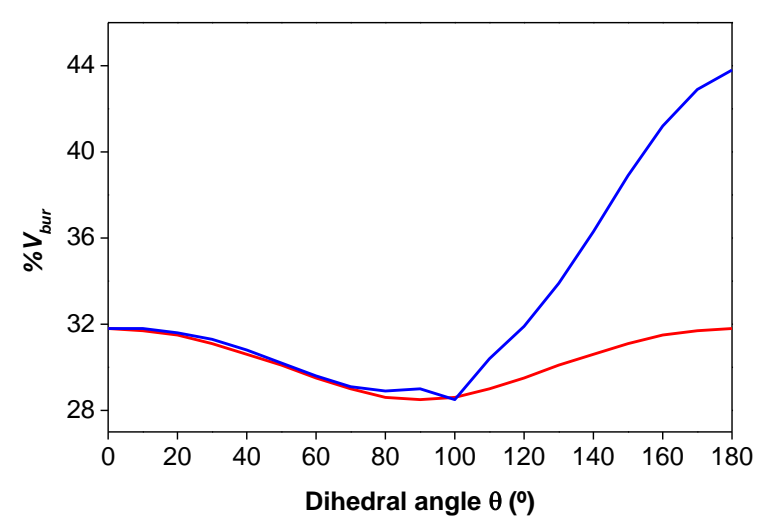

Figure 8. Changing of $\% V_{\text {bur }}$ for 3 and 6 as the phenyl and naphthyl substituent rotates around the $\mathrm{N}-\mathrm{C}$ bond.

As shown in Figure 8, the $\% V_{\text {bur }}$ for both 3 and 6 varry as the phenyl and naphthyl plane rotate around the $\mathrm{C}-\mathrm{N}$ single bond. For carbene 3, a minimum steric bulk $\% V_{\text {bur }}$ of 28.5 is achieved with the phenyl lies perpendicular to 
the triazole ring $\left(\theta=0^{\circ}\right)$. As the phenyl ring rotate, $\% V_{\text {bur }}$ for 3 gradually increases and reaches the maximum of 31.8 when the two planes are coplanar $\left(\theta=0^{\circ}\right.$ or $\left.180^{\circ}\right)$. On the other hand, due to unsymmetrical nature of the naphthyl substituent, as it rotates around the $\mathrm{C}$ $\mathrm{N}$ bond, $\% V_{\text {bur }}$ of 6 varries from $31.8\left(\theta=0^{\circ}\right)$ to $28.5\left(\theta=100^{\circ}\right)$. Further rotation leads to an increase of the steric hindrance as the naphthyl ring is pointed toward the metal center. A maximum $\% V_{\text {bur }}$ of 43.8 is reached when at the dihedral angle of $\theta=180^{\circ}$.

\subsection{Topographic steric map of their metal complexes}

Catalyst design has always been a challenging task and often driven by trial and error, or intuition, rather than a rational science. A classic solution to the problem is to use molecular descriptors capable of visualizing the catalysts space to offer a rational understanding of the designed catalyst. Using SambVca 2 tool, topographic steric map of the carbenes and, therefore, catalytic pocket of their metal complexes can be easily obtained.

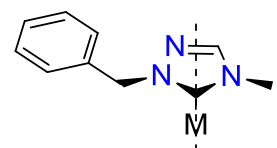

(a) $\quad w$
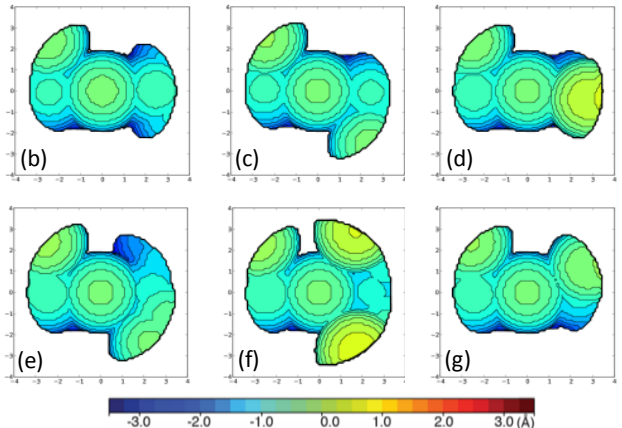

Figure 9. Viewing angle and topographic steric map of NHC metal complexes with 1 (b), 2 (c), 3 (d), 4 (e), 5 (f) and 6 (g) as ligand.
For the six carbenes, when looking at the carbene from the metal center, along the $\mathrm{M}$ $\mathrm{C}_{\text {carbene }}$ bond (Figure 9a), topographic steric map of the carbenes appears as visualized in Figure $9 \mathrm{~b}$-g. The contours represent relative distance to the plane perpendicular to viewing axis and passing through the $\mathrm{C}_{\text {carbene }}$ atom.

Topoghraphic steric map study reveals that the metal coordinated to NHC 1, 3, 6 are relatively accessible from the directions which is perpendicular to the carbene heterocycle planes. On the other hand, in the complex of $\mathbf{5}$, the catalytic pocket is relatively limited in size, and the incoming agent has to approach from direction opposite to carbene $\mathbf{5}$ to reach to the metal center. It is therefore suggested that the complex of $\mathbf{5}$ may not be the best choice of catalyst to activate bulky substrates.

\section{Conclusion}

Stereoelectronic properties of a series of 1,2,4-triazole-derived carbenes bearing different N4-substituents, namely isopropyl, benzyl, phenyl, mesityl, 2,6-diisopropylphenyl and 1naphthyl, has been examined. The results suggest the similarity in nature and energy level of their HOMOs. Steric properties of the NHCs was evaluated and quantified using percent volume burried ( $\% V_{\text {bur }}$ ) methodology. The NHC with isopropyl N4-substituent was the least bulky one and the most bulky is the one with 2,6diisopropylphenyl N4-substituent. Importantly, the NHCs with phenyl and 1-naphthyl N4substituents display flexible steric properties, which were accesible by rotation of the phenyl or 1-naphthyl around the $\mathrm{N}-\mathrm{C}$ single bond.

\section{Acknowledgments}

This work is funded by National Foundation for Science \& Technology Development (NAFOSTED) through the grant No. 104.032017.14. 


\section{References}

[1] D. Bourissou, O. Guerret, F.P. Gabbaï, G. Bertrand, Stable Carbene, Chem. Rev. 100 (2000) 39-92. https://doi.org/10.1021/cr940472u.

[2] N. Marion, S.P. Nolan, Well-Defined NHeterocyclic Carbenes-Palladium(II) Precatalysts for Cross-Coupling Reactions, Acc. Chem. Res. 41 (2008) 1440-1449. https://doi.org/10.1021/ ar800020y.

[3] F.E. Hahn, M.C. Jahnke, Heterocyclic carbenes: synthesis and coordination chemistry, Angew. Chem., Int. Ed. 47 (2008) 3122-3172. http://doi. org/10.1002/anie.200703883.

[4] M.N. Hopkinson, C. Richter, M. Schedler, F. Glorius, An overview of N-heterocyclic carbenes, Nature 510 (2014) 485-496. https://doi.org/ nature 13384 .

[5] W.A. Herrmann, N-Heterocyclic Carbenes: A New Concept in Organometallic Catalysis, Angew. Chem., Int. Ed. 41 (2002) 1290-1309, https://doi.org/10.1002/1521-3773\%2820020415 $\% 2941 \% 3$ A $8 \% 3 C 1290 \% 3$ A\%3AAID-ANIE12 90\%3E3.0.CO\%3B2-Y.

[6] S. Díez-Gonzalez, N. Marion, S.P. Nolan, NHeterocyclic Carbenes in Late Transition Metal Catalysis, Chem. Rev. 109 (2009) 3612-3676. https://doi.org/10.1021/cr900074m.

[7] L. Cavallo, A. Correa, C. Costabile, H.J. Jacobsen, Steric and electronic effects in the bonding of $\mathrm{N}$-heterocyclic ligands to transition metals, Organomet. Chem. 690 (2005) 5407 5413. https://doi.org/10.1016/j.jorganchem.2005. 07.012 .

[8] H. Clavier, S.P. Nolan, Percent buried volume for phosphine and $\mathrm{N}$-heterocyclic carbeneligands: steric properties in organometallic chemistry, Chem. Commun. 46 (2010) 841-861. https://doi. org/10.1039/B922984A.

[9] C. Buron, L. Stelzig, O. Guerret, H. Gornitzka, V. Romanenko, G. Bertrand, Synthesis and structure of 1,2,4-triazol-2-ium-5-ylidene complexes of $\mathrm{Hg}(\mathrm{II}), \mathrm{Pd}(\mathrm{II}), \mathrm{Ni}(\mathrm{II}), \mathrm{Ni}(0), \mathrm{Rh}(\mathrm{I})$ and $\mathrm{Ir}(\mathrm{I}), \mathrm{J}$. Organomet. Chem. 664 (2002) 70-76. https: //doi.org/10.1016/S0022-328X(02)01924-1.

[10] S. Guo, H.V. Huynh, Dinuclear TriazoleDerived Janus-Type N-Heterocyclic Carbene Complexes of Palladium: Syntheses, Isomerizations, and Catalytic Studies toward Direct C5-Arylation of Imidazoles, Organometallics, 33 (2014) 2004-2011. https:// doi.org/10.1021/om500139b.
[11] A. Zanardi, J.A. Mata, E. Peris, Palladium Complexes with Triazolyldiylidene. Structural Features and Catalytic Applications, Organometallics 28 (2009) 4335-4339. https:// doi.org/10.1021/om8010504.

[12] C. Dash, M.M. Shaikh, R.J. Butcher, P. Ghosh, A comparison between nickel and palladium precatalysts of 1,2,4-triazole based Nheterocyclic carbenes in hydroamination of activated olefins, Dalton Trans. 39 (2010) 25152524. http://doi.org/10.1039/B917892A.

[13] H. Clavier, A. Correa, L. Cavallo, E.C. EscuderoAdan, J. Benet-Buchholz, A.M.J. Slawin, S.P. Nolan, $[\mathrm{Pd}(\mathrm{NHC})$ (allyl)Cl] Complexes: Synthesis and Determination of the NHC Percent Buried Volume (\%Vbur) Steric Parameter, Eur. J. Inorg. Chem. 2009 (2009) 1767-1773. https:// doi.org/10.1002/ejic.200801235.

[14] D. Yuan, H.V. Huynh, Hetero-dicarbene Complexes of Palladium(II): Syntheses and Catalytic Activities, Organometallics, 33 (2014) 6033-6043. https://doi.org/10.1021/om500659v.

[15] V.H. Nguyen, I.B. Ibrahim, H.V. Huynh, Postmodification Approach to Charge-Tagged 1,2,4-Triazole-Derived NHC Palladium(II) Complexes and Their Applications Organometallics, 36 (2017) 2345-2353. https:// doi.org/10.1021/acs.organomet.7b00329.

[16] V.H. Nguyen, B.M.E. Ali, H.V. Huynh, Stereoelectronic Flexibility of AmmoniumFunctionalized Triazole-Derived Carbenes: Palladation and Catalytic Activities in Water Organometallics, 37 (2018) 2358-2367. https:/ /doi.org/10.1021/acs.organomet.8b00347.

[17] A.D. Becke, Density-functional thermochemistry. III. The role of exact exchange, J. Chem. Phys. 98 (1993) 5648-5652. https://doi.org/10.1063/ 1.464913.

[18] C. Lee, W. Yang, R.G. Parr, Development of the Colle-Salvetti correlation-energy formula into a functional of the electron density, Phys. Rev. B, 37 (1988) 785-789. https://doi.org/10.1103/ Phys RevB.37.785.

[19] S.H. Vosko, L. Wilk, M. Nusair, Accurate spindependent electron liquid correlation energies for local spin density calculations: a critical analysis, Can. J. Phys. 58 (1980) 1200-1211. https://doi. org/10.1139/p80-159.

[20] P.J. Stephens, F.J. Devlin, C.F. Chabalowski, M.J. Frisch, Ab Initio Calculation of Vibrational Absorption and Circular Dichroism Spectra Using Density Functional Force Fields, J. Phys. 
Chem. 98 (1994) 11623-11627. https://doi.org/ 10.1021/j100096a001.

[21] G.A. Petersson, A. Bennett, T.G. Tensfeldt, M.A. Al-Laham, W.A. Shirley, J. Mantzaris, A complete basis set model chemistry. I. The total energies of closed-shell atoms and hydrides of the first-row elements, J. Chem. Phys. 89 (1988) 2193-2218. https://doi.org/10.10631.455064.

[22] G.A Petersson, M.A. Al-Laham, A complete basis set model chemistry. II. Open-shell systems and the total energies of the first-row atoms, J. Chem. Phys. 94 (1991) 6081-6090. https://doi. org/10.1063/1.460447.

[23] L. Falivene, R. Credendino, A. Poater, A. Petta, L. Serra, R. Oliva, V. Scarano, L. Cavallo, SambVca 2. A Web Tool for Analyzing Catalytic Pockets with Topographic Steric Maps, Organometallics, 35 (2016) 2286-2293. https://doi.org/ 10.1021/acs.organomet.6b00371.

[24] D. Enders, K. Breuer, G. Raabe, J. Runsink, J.H. Teles, J. Melder, K. Ebel, S. Brode, Preparation, Structure, and Reactivity of 1,3,4-Triphenyl-4,5dihydro-1H-1,2,4-triazol-5-ylidene, a New Stable Carbene, Angew. Chem. Int. Ed. Engl. 34 (1995) 1021-1023. https://doi.org/10.1002/anie. 199510211.

[25] C.A. Tolman, Phosphorus ligand exchange equilibriums on zerovalent nickel. Dominant role for steric effects, J. Am. Chem. Soc. 92 (1970) 2956-2965. https://doi.org/10.1021/ja00713a007.

[26] C.A. Tolman, Steric effects of phosphorus ligands in organometallic chemistry and homogeneous catalysis, Chem. Rev. 77 (1977) 313-348. https://doi.org/10.1021/cr60307a002.

[27] A. Immirzi, A. Musco, A method to measure the size of phosphorus ligands in coordination complexes, Inorg. Chim. Acta 25 (1977) L41L42. https://doi.org/10.1016/S0020-1693(00)95 635-4.

[28] B.J. Dunne, R.B. Morris, A.G. Orpen, Structural systematics. Part 3. Geometry deformations in triphenylphosphine fragments: a test of bonding theories in phosphine complexes, J. Chem. Soc., Dalton Trans. (1991) 653-661. https://doi.org/ 10.1039/DT9910000653.

[29] T.L. Brown, A molecular mechanics model of ligand effects. 3. A new measure of ligand steric effects, Inorg. Chem. 31 (1992) 1286-1294. https://doi.org/10.1021/ic00033a029.

[30] H. Clavier, S.P. Nolan, Percent buried volume for phosphine and $\mathrm{N}$-heterocyclic carbeneligands: steric properties in organometallic chemistry Chem. Comm. (2010) 841-861. http://doi.org/ 10.1039/B922984A 